\title{
LEVANTAMENTO SOROLÓGICO DA LEPTOSPIROSE EM CAPRINOS LEITEIROS NO RIO GRANDE DO SUL, BRASIL ${ }^{1}$
}

\author{
SEROLOGICAL SURVEY OF LEPTOSPIRA INFECTION ON DAIRY GOATS \\ HERDS ON THE STATE OF RIO GRANDE DO SUL, BRAZIL
}

\author{
Verônica Schmidt ${ }^{2}$ Alessandra Arosi ${ }^{3}$ Airton da Rosa dos Santos ${ }^{3}$
}

RESUMO

\begin{abstract}
Um estudo sorológico para Leptospira spp. foi realizado em caprinos leiteiros de 15 municípios do Rio Grande do Sul, Brasil. Foram examinados 354 soros frente a 12 sorovares de Leptospira pela técnica da aglutinação microscópica. No momento da coleta do sangue, todos os animais examinados possuíam aspecto saudável e não apresentavam sinais clínicos sugestivos de leptospirose. Dos animais amostrados, 3,4\% apresentaram título 100 ou maior. Os sorovares icterohaemorragiae, pomona e hardjo foram encontrados nos animais soropositivos. Estes resultados confirmam a presença da infecção de caprinos por Leptospira no Rio Grande do Sul e indicam a existência de mais de um sorovar predominantemente nesta espécie na região.
\end{abstract}

Palavras - chave: leptospirose, caprinos, Leptospira

\section{SUMMARY}

A serological survey to detect antibodies against Leptospira spp. was conducted on dairy goats serum samples collected from 15 counties on the State of Rio Grande do Sul, Brazil. Serum samples collected from a total of 354 goats were tested against 12 serological Leptospira serovar, using the microscopic agglutination test. At the time of blood collection, all the animals were clinically examined and no clinical sign suggestive of Leptospirose was observed. The prevalence of positive serum, as determined at dilution of 1:100 or higher, was 3.4\%. Agglutinins against three serovar (icterohaemorragiae, pomona and hardjo) were found in positive animals. These findings are suggestive of the presence of Leptospira infection on goats herds grazed on the State of Rio Grande do Sul and also does suggest the presence of more than one serovar on the herds studied.

Key words: leptospirosis, goats, Leptospira.

\section{INTRODUÇÃO}

A leptospirose é uma zoonose de distribuição universal. $O$ reservatório natural da bactéria é representado por animais silvestres e domésticos, assintomáticos ou não (TRABULSI \& CASTRO, 1999). Como doença, é conhecida desde 1886 por Weil através do diagnóstico clínico no homem; porém a Leptospira como agente causador da doença só foi determinada em 1916, por Inada e colaboradores (OLIVEIRA, 1984).

O gênero compreende as espécies Leptospira biflexa e Leptospira interrogans, ambas subdivididas em vários sorovares. Os sorovares de L. biflexa são de vida livre, enquanto os sorovares de $\boldsymbol{L}$. interrogans abrangem todos os associados a infecções em humanos e animais (TRABULSI \& CASTRO, 1999).

A L. interrogans compreende mais de 180 sorovares de acordo com a composição antigênica. Alguns sorovares parecem ter certas

\footnotetext{
${ }^{1}$ Projeto realizado com apoio financeiro da FAPERGS.

${ }^{2}$ Médico Veterinário, Professor Adjunto, Departamento de Medicina Veterinária Preventiva, Faculdade de Veterinária, Universidade Federal do Rio Grande Sul, Av: Bento Gonçalves, 9090, 91540-000. Porto Alegre, RS. E:mail: veroschmidt@hotmail.com.

${ }^{3}$ Médico Veterinário.
} 
espécies animais como hospedeiros naturais. Entretanto, animais e o homem podem ser infectados com uma grande variedade de sorovares. Os causadores de doença nos animais variam entre os países e as regiões. A maioria das infecções nos animais domésticos em uma região particular é causada por pequeno número de sorovares. Em casos de suspeita de infecção, a sorologia pode ser utilizada como diagnóstico. O título de anticorpos pode variar consideravelmente de animal para animal. $O$ teste de aglutinação microscópica usa leptospiras vivas como antígeno, tem alta sensibilidade e é soroespecífico. O título 100 é suspeito e 200 ou maior é positivo, sendo que títulos iguais ou maiores que 800 indicam infecção ativa (QUINN et al., 1998).

A leptospirose nos caprinos, enquanto doença clínica, não tem sido relatada. Nos casos de infecção natural, os sinais mais evidentes são: perda de peso, icterícia, hemoglobinúria, anorexia, letargia e hipertermia, com duração do quadro por 2 a 4 dias; em fêmeas prenhes têm-se verificado abortos. Nos casos de doença aguda, pode ocorrer uma alta taxa de mortalidade (superior a 40\%). Nesta espécie, os relatos têm-se restringido à freqüência de títulos sorológicos em animais aparentemente saudáveis, sendo que os sorovares mais prevalentes são pomona, autumnalis, sejroe, icterohaemorragiae, gripotyphosa e ballum (WILLIAMS, 1981).

WANYANGU et al. (1993), no Kenya, relataram que a prevalência de anticorpos antileptospiras foi de $16,2 \%$. Os sorovares autumnalis e hardjo foram encontrados em todas as áreas do país, enquanto os sorovares icterohaemorragiae e pomona foram encontrados apenas na região oeste. No Tirol, a prevalência de anticorpos antileptospira estudada em caprinos foi $2,1 \%$ para o sorovar poi (CICERONI et al., 2000). Na Bolívia, de 218 caprinos estudados, $19,7 \%$ foram positivos em diluição 100 ou maior para os sorovares poi e shermani pela técnica de aglutinação microscópica (CICERONI et al., 1997).

Na Paraíba, ALVES (1995) encontrou 0 a $56 \%$ de caprinos soro reatores na pesquisa de aglutininas antileptospira. Em Pernambuco, 33\% dos caprinos de nove cidades foram positivos para leptospirose pelo teste de microaglutinação. Os sorovares prevalentes foram canicola e autumnalis (CUNHA et al., 1999). Na Bahia, 71,6\% dos caprinos testados por CALDAS et al. (1995/6) foram positivos sorologicamente para leptospirose sendo autumnalis, tarassovi, australis e andamana os sorovares mais freqüentes. $\mathrm{Na}$ região da Grande Porto Alegre, foram detectado $14,2 \%$ de caprinos sorologicamente reagentes em título a partir de 100 e
$19,6 \%$ em título 50. Houve $27,2 \%$ de coaglutinações, e o sorovar mais encontrado foi icterohaemorragiae (ABUCHAIM \& SCHMIDT, 1991).

No presente trabalho, objetivou-se determinar a freqüência de aglutininas antileptospiras em rebanhos caprinos leiteiros de 15 municípios do Estado do Rio Grande do Sul.

\section{MATERIAL E MÉTODOS}

Colheram-se 354 amostras de sangue de caprinos, de várias raças, machos e fêmeas, adultos e jovens, provenientes de 22 criatórios ligados à Associação dos Caprinocultores do Rio Grande do Sul - Caprisul, de 15 municípios do Rio Grande do Sul, para pesquisa de aglutininas anti-leptospiras. O soro obtido foi colocado em frascos esterilizados, tipo penicilina de $20 \mathrm{~m} \ell$ e armazenados em congelador a $-20^{\circ} \mathrm{C}$ até o momento do uso.

Para as provas de aglutinação microscópicas, foram usadas culturas vivas de Leptospira dos seguintes sorovares: icterohaemorragiae (RGA), canicola (Hond Utrech), castelonis (castellón 3), pyrogines (Salinem), autumnalis (Akyami A), australis (Ballico), pomona (Pomona), gripotyphosa (Moskva V), hardjo (Hardjopratino), hebdomadis (Hebdomadis), bataviae (Van Thienen) e tarassovi (Perepelicin).

As amostras de soro obtidas foram submetidos à prova de aglutinação microscópica utilizada por RECKZIEGEL (1994).

\section{RESULTADOS}

Dos 22 criatórios amostrados, 3 (13,64\%) apresentaram animais reagentes em título $100 \mathrm{ou}$ maior e 7 (31,81\%), em título 50. Das 354 amostras coletadas, $12(3,4 \%)$ apresentaram título 100 ou maior e $44(12,5 \%)$ reagiram em diluição 1:50. As demais $(84,1 \%)$ foram não reagentes. Seis $(1,7 \%)$ dos soros reagentes em título 100 ou maior o foram frente a mais de um sorovar, considerando-se, para fins de tabulação dos dados, o sorovar cujo título foi mais alto. Dentre os soros que reagiram em diluição 100 ou mais, a distribuição ocorreu da seguinte forma: 3 animais reagentes em título 100; 3 animais reagentes em título 200; 5 animais reagentes em título 400 e um animal reagente em título 800 (Tabela 1). Em relação ao sorovar encontrado, considerando o título 100 ou mais, obteve-se: icterohaemorragiae $(2,5 \%)$, hardjo $(0,6 \%)$ e pomona $(0,3 \%)$ (Tabela 2$)$. Houve reação frente aos sorotipos canicola e wolffi em título 50 . 
Tabela 1 - Número de caprinos reagentes ao teste de soroaglutinação microscópica em título 100 ou maior, frente sorovares de Leptospira interrogans prevalentes em 15 municípios do Estado do Rio Grande do Sul.

\begin{tabular}{lccccc}
\hline & \multicolumn{5}{c}{ TÍTULOS } \\
\cline { 2 - 6 } SOROVARES & 100 & 200 & 400 & 800 & Total \\
\hline icterohaemorragiae & 2 & 3 & 3 & 1 & 9 \\
hardjo & 1 & - & 1 & - & 2 \\
pomona & - & - & 1 & - & 1 \\
Total & 03 & 03 & 05 & 1 & 12 \\
\hline
\end{tabular}

Tabela 2 - Freqüência de sorovares reagentes ao teste de aglutinação microscópica para leptospira em 354 soros de caprinos de 15 municípios do Estado do Rio Grande do Sul.

\begin{tabular}{lcc}
\hline & \multicolumn{2}{c}{ POSITIVOS } \\
\cline { 2 - 3 } SOROVARES & $\mathrm{N}^{\circ}$ & $\%$ \\
\hline icterohaemorragiae & 9 & 2,5 \\
hardjo & 2 & 0,6 \\
pomona & 1 & 0,3 \\
Total & 12 & 3,4
\end{tabular}

Tabela 3 - Distribuição dos sorovares de Leptospira interrogans infectando caprinos, em 15 municípios do Estado do Rio Grande do Sul.

\begin{tabular}{cc}
\hline MUNICÍPIO & SOROVARES \\
\hline Farroupilha & icterohaemorragiae, pomona, hardjo \\
Porto Alegre & icterohaemorragiae, hardjo \\
São Leopoldo & icterohaemorragiae \\
Ivoti & icterohaemorragiae, pomona \\
Taquara & icterohaemorragiae, canicola, pirogynes, pomona \\
Gravataí & pomona \\
Barão do Triunfo & pomona \\
\hline
\end{tabular}

A distribuição dos sorovares em relação aos municípios pode ser observada na tabela 3 . Nos municípios de Viamão, Glorinha, Bento Gonçalves, Osório, Guaíba, Mariana Pimentel, Cachoeirinha e Encantado não se verificaram animais reagentes em título sorológico maior ou igual a 50; nos municípios de Ivoti, Taquara, Barão do Triunfo e Gravataí não se verificaram animais reagentes em título sorológico maior ou igual a 100 .

\section{DISCUSSÃO}

A prevalência encontrada $(3,4 \%)$ foi menor do que a esperada, segundo os resultados registrados por ABUCHAIM \& SCHMIDT (1991) $(14,2 \%)$, na região da Grande Porto Alegre. No entanto, a prevalência de animais com título sorológico $50 \quad(12,5 \%)$ foi mais próxima do anteriormente encontrado por estes mesmos autores $(19,6 \%)$. Esta diferença pode estar relacionada ao fato de que o título sorológico pode variar de animal para animal e desconhece-se a permanência deste título em caprinos naturalmente infectados.

Seguindo a idéia de QUINN et al. (1998), de que em uma região particular há um pequeno número de sorovares causando infecção, os sorovares utilizados neste estudo foram selecionados enquanto representativos dos sorovares prevalentes infectando outras espécies de animais de produção em nosso Estado. Os sorovares encontrados (icterohaemorragiae, pomona e hardjo) discordam dos dados registrados em estudos na espécie caprina no Brasil, bem como em outros países sendo esperado que os sorotipos causadores de doença nos animais variem entre países e entre regiões.

Embora tenhamos encontrado animais com título sorológico 200, 400 e 800 , o que caracterizaria infecção crônica nos primeiros e ativa nos últimos, não houve relato de sintomatologia clínica compatível com leptospirose nos criatórios de origem destes animais, o que também tem sido observado por outros autores.

Tendo em vista que os animais amostrados no presente estudo são animais de cabanha (matrizes e reprodutores para comercialização), a estrutura de produção e manejo, como semi-confinamento ou confinamento, alimentação equilibrada, controle de roedores e vetores, programa sanitário de vacinações e everminações, entre outros, são fatores diferenciadores dos demais sistemas de produção (familiar, cooperativado, entre outros), os quais poderiam influenciar nestes resultados.

Embora ALVES (1995) tenha observado que existe associação entre a proporção de animais soro-reagentes para a leptospirose e os índices pluviométricos acumulados, mas não com as variáveis temperatura ambiente e o tipo de manejo zoosanitário, estes aspectos não foram contemplados no presente trabalho, o que nos permite desenhar um estudo futuro que contemple a estrutura epidemiológica da leptospirose em rebanhos caprinos do Estado, uma vez que a infecção por leptospira está presente em caprinos leiteiros no Estado do Rio Grande do Sul e existe mais de um sorovar causando infecção.

\section{CONCLUSÃO}

A infecção por leptospira está presente nos caprinos leiteiros no Estado do Rio Grande do Sul com prevalência dos sorovares icterohaemorragiae, hardjo e pomona. 


\section{REFERÊNCIAS BIBLIOGRÁFICAS}

ALVES, C.J. Influência de fatores ambientais sobre a proporção de caprinos soro-reatores para a leptospirose em cinco centros de criação do estado da Paraíba, Brasil. São Paulo, SP, 1995. 104p. Tese (Doutorado) - Curso de Pós-graduação em Medicina Veterinária e Zootecnia, Universidade de São Paulo, 1995.

ABUCHAIM, D.M., SCHMIDT, V. Prevalência da Leptospirose em caprinos provenientes de propriedades da Grande Porto Alegre. Arquivos da Faculdade de Veterinária, Porto Alegre, v.19, p.15 - 19, 1991.

CALDAS, E.M., VIEGAS, E. de A., REIS, R. de S., et al. Estudo comparativo entre estirpes de $L$. interrogans e L. biflexa no diagnóstico de triagem de leptospira em animais. Arquivos da Escola de Medicina Veterinária da Universidade Federal da Bahia, Salvador, v.18, n.1, p.126 - 140, 1995/6.

CICERONI, L., BARTOLINI, A., PINTO, A., et al. Serological survey of leptospiral infections in sheep, goats and dogs in Cordillera Province, Bolivia. New Microbiology, n.20, v.1, p.77 - 81, 1997.

CICERONI, L., LOMBARDO, D., PINTO, A., et al. Prevalence of antibodies to Leptospria serovars in sheep and goats in Alto Adige-South Tyrol. Journal Vet Med B Infect Dis Vet Public Health, v.47, n.3, p.217 - 223, 2000.
CUNHA, E.L.P., MOTA, R.A., MEIRELES, L., et al. Pesquisa de aglutininas antileptospiras em soros de caprinos no Estado de Pernambuco, Brasil. Revista Brasileira de Medicina Veterinária. v.21, n.1, p.38 - 40, 1999.

OLIVEIRA, S. Leptospira. In: GUERREIRO, M. (ed).. Bacteriologia. Porto Alegre : Sulina, 1984. Cap.39. p.463 483.

QUINN, P.J., CARTER, M.E., MARKEY, B.K., et al. Clinical Microbiology. London : Mosby, 1998. 648p. Cap. 31: The spirochaets: p.292-309.

RECKZIEGEL, A.M. dal S. Leptospirose: sensibilidade e especificidade do teste de diagnóstico por soroaglutinação microscópica em bovinos com presença renal do agente. Porto Alegre, RS, 1994. 61p. Dissertação (Mestrado) Curso de Pós-graduação em Ciências Veterinárias, Universidade Federal do Rio grande do Sul, 1994.

TRABULSI, R.L, CASTRO.A.F.P. Espiroquetídeos. In: TRABULSI, R.L, ALTERTHUM, F., GOMPERTZ, O.F., et al. Microbiology. 3.ed. São Paulo : Ateneu, 1999. Cap.41, p.315 - 320

WANYANGU, S.W., ANGOLIO, A., WAMWAYI, H.M. Further serological evidence for caprine leptospirosis in Kenya. East-African-Agricultural-and-Forestry Journal, v. 59 , n.2, p.137 - 143, 1993

WILliAMS, C.S.F. Diseases. In: GALL, C. (ed). Goat production. London : Academic, 1981. p.433 - 487 